\title{
Dielectric sample with two-layer charge distribution for space charge calibration purposes
}

\author{
Holbøll, Joachim; Henriksen, Mogens; Rasmussen, C.
}

Published in:

2002 Annual Report, IEEE Publication 02CH37

Link to article, DOI:

10.1109/CEIDP.2002.1048879

Publication date:

2002

Document Version

Publisher's PDF, also known as Version of record

Link back to DTU Orbit

Citation (APA):

Holbøll, J., Henriksen, M., \& Rasmussen, C. (2002). Dielectric sample with two-layer charge distribution for space charge calibration purposes. In 2002 Annual Report, IEEE Publication $02 \mathrm{CH} 37$ (pp. 648-651). IEEE. https://doi.org/10.1109/CEIDP.2002.1048879

\section{General rights}

Copyright and moral rights for the publications made accessible in the public portal are retained by the authors and/or other copyright owners and it is a condition of accessing publications that users recognise and abide by the legal requirements associated with these rights.

- Users may download and print one copy of any publication from the public portal for the purpose of private study or research.

- You may not further distribute the material or use it for any profit-making activity or commercial gain

- You may freely distribute the URL identifying the publication in the public portal 
2002 Annual Report Conference on Electrical Insulation and Dielectric Phenomena

\title{
Dielectric sample with two-layer charge distribution for space charge calibration purposes
}

\author{
Joachim T. Holbøll ${ }^{1}$, Mogens Henriksen ${ }^{1}$ and Claus Rasmussen ${ }^{2}$ \\ ${ }^{1}$ Technical University of Denmark, Dept. of Electric Power Eng., Lyngby, DENMARK \\ ${ }^{2}$ NKT-Research, Elektrovej, Lyngby, DENMARK
}

\begin{abstract}
In the present paper is described a dielectric test sample with two very narrow concentrations of bulk charges, achieved by two internal electrodes not affecting the acoustical properties of the sample, a fact important for optimal application of most space charge measuring systems. Space charge formation was investigated under different electrical conditions by means of the laser induced pressure pulse (LIPP) method and the pulsed electro-acoustic method (PEA).
\end{abstract}

\section{Introduction}

It is well known that the formation of space charges affects the performance of the insulation of HVDCequipment. Correct calibration and evaluation of space charge measuring equipment needs the establishment of a well-defined charge distribution in the device under test or in a specific test sample suitable for calibration purposes. Often, calibration is based on the electrode charges, a procedure which not necessarily corresponds to the conditions present inside the insulation.

Earlier measurements have shown that test system calibration based on the interface charge on external electrodes involves a risk of misinterpretation in case of acoustic discontinuities [1]. For that reason, a test sample with a very narrow and constant space charge distribution is desirable for the following reasons:

- It gives the possibility of direct evaluation of the spatial resolution, attenuation and signal distortion.

- The measuring results easily show the need, for and the effect of, system improvements.

- The measured space charge distributions directly show the system response to very narrow signals necessary for deconvolution methods to be applied to the results.

A test sample was developed earlier [1] with one thin, chargeable gold layer implemented in a homogeneous dielectric of cast PMMA. Charging is easily done by voltage application to the gold layer. PMMA has shown to be suitable for calibration purposes because of low attenuation and distortion, as compared to, for example, LDPE [2].
The improved two-layer sample described in the present paper is a further improvement and completion of this work.

\section{Dielectric sample with two charge layers}

The two disadvantages of one-layer samples are:

- The resulting field and, consequently, the charge density on the charge layer is dependent on the distance to the external electrodes and all materials involved in the contact area.

- It is difficult to distinguish between system response to the narrow charge distribution and possible space charge formation adjacent to the charge layer.

The improved sample includes two internal gold layers in a homogeneous dielectric, with full potential control of these layers. The thickness of the gold layers can be considered as being negligible, compared to the spatial resolution of available detection systems.

\section{Principle}

The idea is to connect the gold layers to the external electrodes in order to limit the electrical field to the area between the layers. In principle, any voltage could be applied to the gold layers, but if formation of space charges has to be excluded for proper pulse shape evaluation, zero electrical field $E_{D C}$ is necessary in the areas between gold layer and external electrode (fig 1).

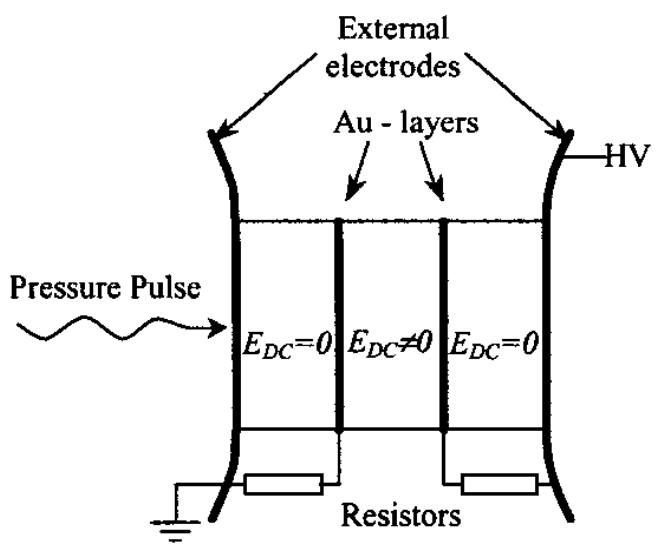

Figure 1: Two very narrow charge distributions achieved by thin gold layers, high resistively connected to the external electrodes. 
By connection of the gold layers to the external electrodes via suitable resistors, the following is achieved:

a) The electrical field $E_{D C}$ is limited to the area in between the gold-layers, giving a well-defined charge density independent of contact and shape of the external electrodes.

b) Possible bulk space charge formation adjacent to the gold layers can occur between the gold layers only, and, consequently, give different pulse shapes for the two main peaks in the measured space charge signal originating from the gold layers. In other words, identical peaks confirm the signal peaks being the system response to a very narrow charge distribution in the gold layers only.

c) With resistors of sufficient high resistance, the transient current between gold layer and external electrode is zero under application of a pressure pulse (LIPP) or an electric field change (PEA). This means the charge on the gold layers can be considered to be constant and not affected by the measurement.

\section{Sample preparation}

A gold layer of $50 \mathrm{~nm}$ thickness and $30 \mathrm{~mm}^{\sigma}$ in diameter was evaporated concentrically on each side of a circular sample of $0.5 \mathrm{~mm}$ or $1 \mathrm{~mm}$ PMMA, $100 \mathrm{~mm}^{\text {a }}$ (figure 2). In addition, circular $0.5 \mathrm{~mm}$ PMMA covers, $28 \mathrm{~mm}^{\circ}$ were concentrically placed on top of each gold layer, with the gold layer protruding $1 \mathrm{~mm}$ in order to give electrical access. The three pieces were hereafter bonded by heat and pressure only, without any additional adhesive. This procedure ensures a sample that is acoustically homogeneous as possible.

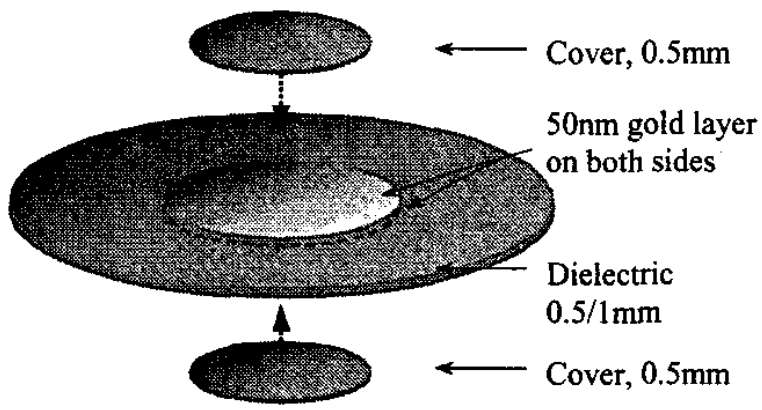

Figure 2: Test sample. Dielectric of $0.5 / 1 \mathrm{~mm}$ PMMA with $50 \mathrm{~nm}$ gold evaporated on both sides. $0.5 \mathrm{~mm}$ PMMA covers fixed on each side without adhesive giving an acoustical homogeneous sample.
The electrical connections from the gold layers to the external electrodes are shown in figure 3 .

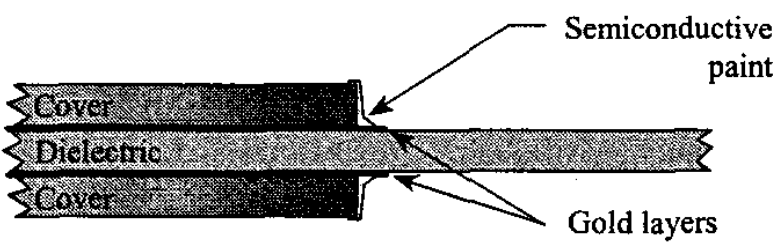

Figure 3: Electrical connection between 50nm gold layers and external electrodes (not shown) by means of semiconductive paint.

The connections are made by means of semiconducting paint, hereby forming good DC-contact but decoupling transient signals.

\section{Measurements}

The new sample was tested at different voltages by means of the laser induced pressure pulse (LIPP) method and the pulsed electro-acoustic method (PEA).

\section{LIPP}

The LIPP measurement principle is well known [3] and in the case of an open detection circuit, the voltage $u(t)$ measured can be described as

$$
u(t)=k \cdot \int E(x) p(x, t) d x,
$$

where $E(x)$ is the electrical field strength, $p(x, t)$ is the pressure pulse as function of location and time and $k$ is a constant. It has been shown [4] that in the case of $p(x, t)$ being a narrow pressure pulse, the voltage signal becomes a direct measure of the electrical field and the differentiation gives the space charge distribution. In our system the laser pulse absorbed by the target to be placed on the test sample was $8 \mathrm{~ns}$ wide.

The coupling capacitor on the high voltage side was $1.67 \mathrm{nF}$ and the input impedance of the amplifier was $1 \mathrm{M} \Omega$. The $3 \mathrm{~dB}$ lower frequency limit of the amplifier was $0.05 \mathrm{MHz}$.

\section{PEA}

The PEA-system measures space charge distributions as the pressure pulse, which originates from space charges affected by a short change of an applied electrical field [5]. In the present system, the field change is generated by a $2 \mathrm{kV}, 20 \mathrm{~ns}$ voltage pulse. The pressure pulse was measured by means of a $28 \mu \mathrm{m}$ PVDF-film coupled to a $2 \times 24 \mathrm{~dB}$ amplifier system with an input impedance of $1 \mathrm{M} \Omega$. The $3 \mathrm{~dB}$ lower frequency limit of each of the amplifiers was $0.1 \mathrm{MHz}$. 


\section{Calibration}

Calibration was performed based on the integral $v_{s} \int_{\text {peak }} u(t) d t$ over one peak of the measured voltage signal $u(t)$ related to the easily calculated flux density on the gold layers under a known DC-voltage applied. $v_{s}$ is the speed of sound in PMMA. The LIPP-system measures the electrical field, i.e. $\int_{\text {peak }} u(t) d t$ can be taken directly from the measured voltage step.

\section{Results and Discussion}

All $1 \mathrm{~mm}$ and $0.5 \mathrm{~mm}$ samples were tested at $0,5,10$, $15 \mathrm{kV}$ in order to check linearity with voltage and possible space charge formation in the bulk. Noise reduction was achieved by averaging over 3 and 10 measurements for the PEA and the LIPP, respectively.

All curves were taken under stable conditions, no temporal development of the charge distributions could be observed within the maximum time, with voltage, of 10 minutes.

Figures 4 and 5 show the LIPP-measured electric field and the derived charge distribution, respectively, in a $1 \mathrm{~mm}$ sample.

The pulse shape and magnitude of the two peaks appears to be identical. The shape is characterized by a sharp leading edge and a slower falling edge, reflecting the shape of the pressure pulse propagating through the sample. Also can be seen that attenuation and distortion can almost be neglected in $1 \mathrm{~mm}$ PMMA, as expected from earlier results [2].

Linearity check based on applied voltage variations revealed no significant non-linearities, confirming the absence of space charge formation.

For the LIPP method, a target has to be applied on the sample for laser pulse absorption and the method can be used for target material optimization.

Figure 6 shows the charge distribution in the same $1 \mathrm{~mm}$-sample measured with the PEA-system. Again, two almost identical peaks can be seen at all voltages with a sharp leading edge but with a slightly distorted falling edge. The resolution of the PEA-system is very similar to that of the LIPP. Most significant in the PEAsignal is the overshoot visible after the first peak and which is still above zero when the signal from the second layer occurs. Subtracting this offset from the second peak shows exactly the same overshoot. Since the electrical field is zero before the first and after the second peak, space charge formation can be excluded as cause of the positive bulk signal. The reason for the distortion has to be found in the detection system.

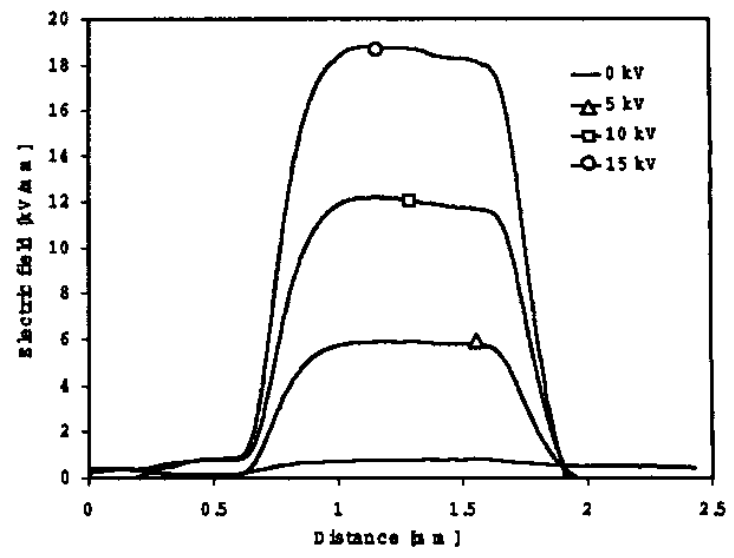

Figure 4: LIPP measured electrical field distribution $E(x)$ in $1 \mathrm{~mm}$ sample with $0-15 \mathrm{kV}$ DC applied to gold layers.

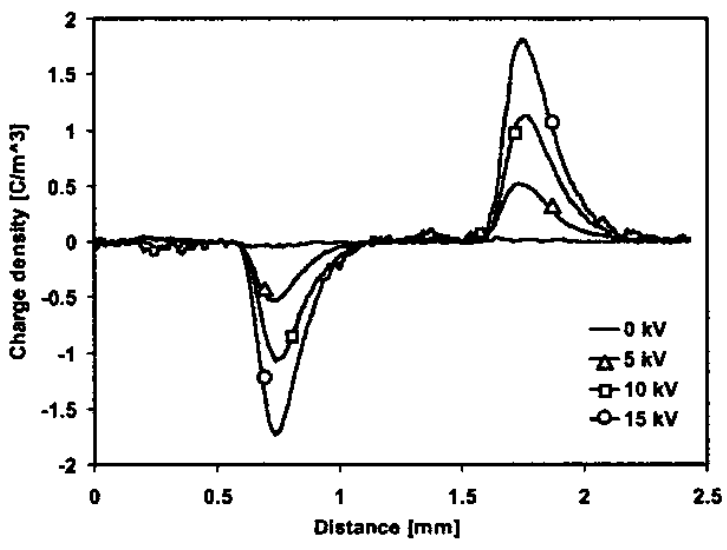

Figure 5: LIPP space charge distribution in $1 \mathrm{~mm}$ sample with $0-$ $15 \mathrm{kV} \mathrm{DC}$ applied to gold layers.

The input of the amplifiers used in the PEA-system is

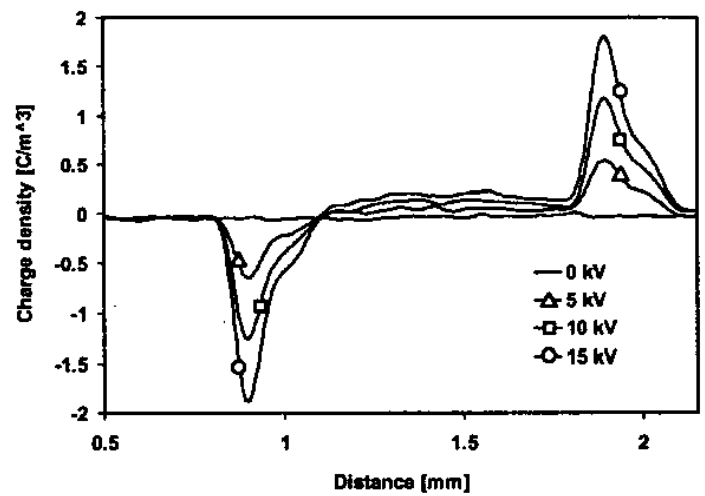

Figure 6: PEA space charge distribution in $1 \mathrm{~mm}$ sample with 0 $15 \mathrm{kV} \mathrm{DC}$ applied to gold layers. 
AC-coupled and simple calculations of the amplifiers pulse response show exactly the same overshoot as measured with the present PEA-system. This confirms, in connection with the exclusion of bulk space charges, the bandwidth of the amplifiers as being the reason for the distortion of the signal.

Looking at the results from $0.5 \mathrm{~mm}$ samples similar responses could be observed as shown in figures 7 and 8 for LIPP and PEA measurements, respectively.

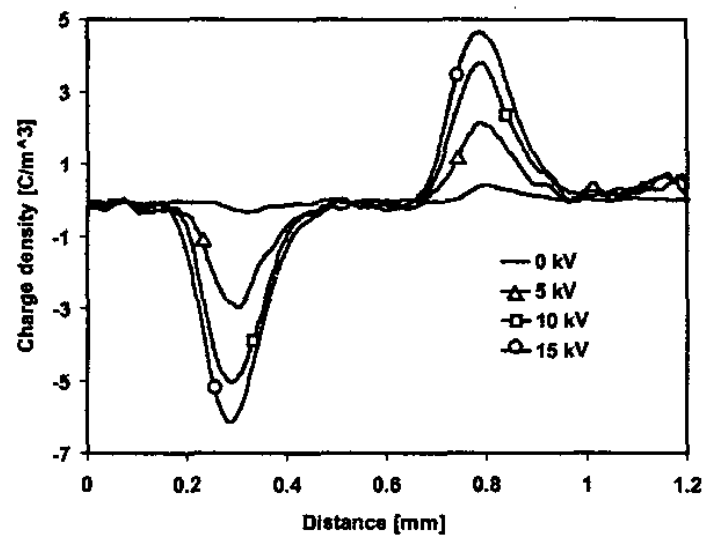

Figure 7: LIPP space charge distribution in $0.5 \mathrm{~mm}$ sample with 0 $15 \mathrm{kV}$ DC applied to gold layers.

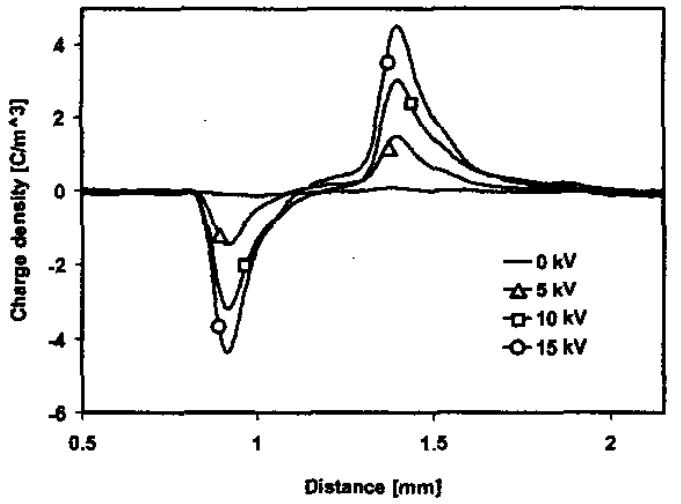

Figure 8: PEA space charge distribution in $0.5 \mathrm{~mm}$ sample with 0 $15 \mathrm{kV}$ DC applied to gold layers.

The PEA-measured space charge distribution in $0.5 \mathrm{~mm}$ samples again is affected by the amplifier system. The first part of the overshoot is clearly visible after both peaks.

As a consequence of the findings, the detection system should be improved by replacing the amplifiers. Alternatively, application of deconvolution methods could be considered since the measurement results directly show the systems response to a well-defined charge distribution to be used as input value.

\section{Conclusion}

A new, planar test sample has been developed giving the possibility of generation of two infinite thin charge layers inside a dielectric without affecting the acoustic homogeneity of the sample.

The potential of two conducting gold layers can be controlled in such a way that the influence of external electrodes can be eliminated.

Samples of $0.5 \mathrm{~mm}$ and $1 \mathrm{~mm}$ thickness between the gold layers have been tested in two different systems for measurement of space charge distributions

At fields up to $30 \mathrm{kV} / \mathrm{mm}$ and within a short time scale no space charge formation could be observed in the bulk or near the charge layers.

Due to the presence of two charge layers, possible space charge formation can easily be identified. Identical peak shape means no space charge formation affecting the signal, i.e. true system response to infinite thin charge layers.

The results confirm the new sample as being very suitable for evaluation of space charge measurement systems performance and limitations.

\section{References}

[1] J.T. Holbøll, J. Hjerrild, M. Henriksen, "Dielectric Sample with Narrow Bulk Charge Distribution", Int. Conf. on Conduction and Breakdown in Solids, pp. 493-496, Eindhoven, 2001.

[2] Y. Li, "Space Charge Measurement in Lossy Solid Dielectric Materials by Pulsed Electroacoustic Method", Ph.D.-Thesis, Musashi Institute of Technologi, Japan, March 1994.

[3] J. Lewiner, "Evolution of Experimental Techniques for the Study of the Electrical Properties of Insulating Materials", IEEE Transactions on Electrical Insulation, vol.21, pp. 351-360, 1986.

[4] R. Gerhard-Multhaupt, "Analysis of Pressure-wave Methods for the Nondestructive Determination of Spatial Charge or Field Distributions in Dielectrics", Phys. Rev. B, Vol.27, No.4, pp. 2494

[5] T. Takada, Y. Li, "Pulsed electroacoustic techniques to characterize charge accumulation properties", Sixth International Conference on Dielectric Materials, Measurements and Applications, pp. $104-107,1992$.

Author's address: Joachim T. Holbøll, Technical University of Denmark, Dept. of Electrical Power Engineering, Elektrovej, Building 325, DK-2800 Lyngby, Denmark, Email: jth@eltek.dtu.dk. 